\title{
Política, trajetória e formação dos atores culturais: uma análise dos projetos contemporâneos
}

\author{
Rodrigo Manoel Dias da Silva*
}

Resumo: O artigo realiza uma análise dos projetos culturais contemporâneos, discutindo algumas interfaces entre as trajetórias de vida de atores e as condições institucionais que circunscrevem as políticas de cultura, tomando-as como um espaço de negociação. Analiticamente, o autor observa que os projetos são tangenciados por permanentes apelos à formação dos atores culturais, constituindo novos repertórios de ação.

Palavras-chave: Políticas culturais; trajetória individual; projetos; formação cultural

Abstract: The article presents an analysis of contemporary cultural projects, discussing some interfaces between the life trajectories of actors and the institutional conditions for circumscribe the political culture, taking them as a space for negotiation. Analytically, the author notes that the projects are tangential to the appeals by permanent training of cultural actors, constituting new repertoires of action.

Keywords: Cultural policies; individual trajectory; projects; cultural training

*Professor de Sociologia e Ciência Política na Universidade Federal da Fronteira Sul (UFFS). Doutorando e Mestre em Ciências Sociais na Universidade do Vale do Rio dos Sinos (UNISINOS). Bolsista CAPES. 


\section{Definindo uma situação}

Canela é um município situado no Estado do Rio Grande do Sul, na região da Serra Gaúcha, distante 130 quilômetros da capital Porto Alegre. Do ponto de vista histórico, pelo menos desde a década de 1920, a cidade tem se constituído como espaço de pessoas em trânsito, assim entendido pelo intenso fluxo de pessoas que passavam pelo lugar seja pela chegada da estação de trem, no ano de 1924, ou pelos últimos agrupamentos de tropeiros que atravessavam a Região Sul conduzindo animais e cargas na direção de outros Estados. A mesma década favoreceu que esse trânsito fosse se intensificando com a chegada dos primeiros veranistas, uns chegavam pelas condições climáticas de uma região serrana, uma vez que recebiam prescrições médicas para tal estada, outros chegavam com o trem e a necessidade de realizar atividades comerciais na região. A intensificação dos fluxos de visitantes começou a mobilizar o surgimento de hotéis e condições de hospedagem. O que ficou evidente, segundo os registros históricos (STOLTZ, 1992; OLIVEIRA; VEECK; REIS, 2009), é que as décadas posteriores consolidaram a região como turística, com significativo ingresso de visitantes em alguns momentos do ano.

Ao mesmo tempo, esta presença de turistas, ou veranistas, não alterava a dinâmica do município. Canela seguia com o passo de cidade do interior, com suas dinâmicas comerciais incipientes, mas em expansão, pequenos segmentos industriais em desenvolvimento (setor madeireiro, dentre outros) e um crescimento da população urbana que passava a se sobrepor à rural. As décadas subsequentes evidenciaram outras particularidades no lugar: as intensas atividades culturais que vinham sendo desenvolvidas. Eram nascentes os grupos de canto, de danças de salão, de atividades desportivas ou lúdicas, as sociedades recreativas, os grupos de teatro amador, grupos de artesãos, assim como outras manifestações culturais. Havia em Canela, na década de 1970 e início de 1980, uma crescente atmosfera de produção e circulação de arte e cultura, basta considerarmos que no período havia vinte e dois grupos de teatro amador.

Embora esses grupos de teatro preservassem seu amadorismo, isso não impediu que delineassem seu próprio circuito de produção e fruição desta arte, surgiam os primeiros festivais de teatro amador do município. $\mathrm{O}$ fim desta década nos apresentou novas tendências para os promotores de teatro: a necessária profissionalização dos atores locais, face às novas definições dos festivais que tornaram-se internacionais, inserindo-se em circuitos de cultura mais abrangentes; ou a interpenetração ou mútua dependência entre os grupos de atores locais e as exigências dos eventos turísticos que precisavam ser enriquecidos por atividades culturais. No entanto, as redefinições nas relações entre os atores locais e o circuito cultural mais amplo são tecidas no âmbito das trajetórias dos atores culturais, delineadas desde políticas culturais recentemente implementadas. Assim, estamos interessados em discutir algumas interfaces entre as trajetórias de vida destes agentes culturais e as condições institucionais que circunscrevem as políticas de cultura tomando-as como um espaço de negociação para propostas de projetos culturais, na atualidade. 
Política, trajetória e formação dos atores culturais:

uma análise dos projetos contemporâneos

Para tal objetivo, segmentaremos, didaticamente, este artigo em três seções textuais. $\mathrm{Na}$ primeira, efetuaremos uma revisão teórica da categoria 'projeto', utilizando, principalmente, duas contribuições teóricas que se complementam, não obstante as suas distinções: a Teoria da Ação Social de Max Weber e a Fenomenologia de Alfred Schutz. Na segunda, realizaremos a descrição de duas trajetórias individuais de atores culturais de Canela, interessados em compreender, desde seus projetos de ação, algumas transformações nas relações entre os atores e as políticas culturais que produzem. Na última, ampliando a discussão, procederemos uma análise dos projetos culturais na contemporaneidade, tendo em vista as novas exigências de ação postas aos atores, nas imbricadas relações entre suas trajetórias e as condições políticas de nosso tempo.

\section{Abordagens teóricas da ação social}

Desde antes de sua institucionalização nos meios acadêmicos, as Ciências Sociais têm se constituído como um ramo do conhecimento interessado em explicar de maneira objetiva a ação humana em sociedade. Florestan Fernandes (2008), ao revisitar a herança intelectual da Sociologia, havia identificado a Filosofia da Ação Humana como um momento do pensamento social, que se distinguiria em três níveis: Filosofia da História, Filosofia Social e Filosofia Política. A caracterização da ação no âmbito de uma vida coletiva configurava o horizonte das nascentes interrogações sociológicas sobre o mundo social.

No entanto, foi na Escola de Sociologia Alemã que o conceito de ação, ou ação social, adquiriu maior relevância e consistência teórica, sobremaneira situado nas teorizações de dois eminentes pensadores sociais clássicos: Max Weber e Georg Simmel.

Max Weber (2008) trouxe-nos a ideia de que a ação social orienta-se pela ação dos outros, as quais poderiam ser passadas, presentes ou esperadas como futuras. Essa afirmativa, inicialmente, trouxe-nos uma ambiguidade entre os limites ou as liminaridades entre considerarmos uma ação individual ou social, uma vez que "nem toda espécie de ação - incluindo a ação externa - é 'social"' (WEBER, 2008, p. 139). O próprio Weber identifica esta imprecisão e segue sua distinção acrescentando que nem toda espécie de contato entre os homens seria de caráter social, somente aquelas dirigidas, com sentido próprio, pela ação de outros ${ }^{1}$

Quando o autor acrescenta a prerrogativa do sentido, ou de uma ação significativa orientada pela ação alheia, sustenta que a ação social não se identifica

${ }^{1}$ Quanto aos sentidos que orientam a ação social, Weber (2008), a partir de sua conhecida construção metodológica dos tipos ideais, menciona que poderiam existir quatro tipificações, não únicas ou puras: racional com relação a fins, racional com relação a valores, afetiva e tradicional. 
com uma ação homogênea de muitos, tampouco, que todas as ações de alguém influenciem ou sejam influenciadas pela ação dos outros. Quando a conduta de vários é reciprocamente dotada de conteúdo significativo, orientando-se pela reciprocidade, temos uma "relação social" (WEBER, 2008). Ou seja, a relação social consiste "na probabilidade de que se agirá socialmente numa forma indicável (com sentido)" (WEBER, 2008, p. 142), no entanto, esses sentidos não são produzidos de forma idêntica pelos atores envolvidos, mas os mesmos mantêm referências mútuas de suas ações. Aqui nos parece um limite heurístico da abordagem de Max Weber sobre a ação social, qual seja: como definirmos as referências mútuas de ação?

A sociologia de Georg Simmel, por sua vez, potencializa um entendimento de sociedade que centraliza as interações sociais. Assim:

A sociedade existe onde quer que vários indivíduos entram em interação. Esta ação recíproca se produz sempre por determinados instintos (Trieben) ou para determinados fins (SIMMEL, 1983, p. 59).

Quais seriam esses fins ou instintos?

Instintos eróticos, religiosos ou simplesmente sociais; fins de ataque ou defesa, de jogo ou ganho, de ajuda ou instrução, estes e infinitos outros fazem com que o homem se encontre num estado de convivência com outros homens, com ações a favor deles, em conjunto deles, contra eles, em correlação de circunstâncias com eles. Numa palavra, que exerça influência sobre eles e por sua vez receba deles (idem, p. 59-60).

Essas interações significam que os atores, sob seus fins específicos ou instintos, constroem referências mútuas de ação (WEBER, 2008), ou influências recíprocas (SIMMEL, 1983), na razão em que convertem-se em 'sociedade'2. Essa suposta unidade social, ou sociação, pode ter diversos graus de acordo com a forma ou o conteúdo da relação.

A sociação, portanto, somente começa a existir quando a coexistência isolada dos indivíduos adota determinadas formas de cooperação ou de colaboração, sob condições de interação social. A partir desse olhar simmeliano à sociedade, faz-se possível depreender correspondências à contribuição de Weber, sobretudo no que tange à ação social orientada por sentidos significativos. Ou ainda, os sentidos atribuídos à ação social são construídos pelos próprios atores

${ }^{2}$ Por outros tangenciamentos ao conceito de sociedade, em oposição às formas comunitárias, em relações condicionantes com o Estado, cf. Tönnies (1973). 
Política, trajetória e formação dos atores culturais:

uma análise dos projetos contemporâneos

desde suas experiências pessoais, seus desejos, interesses ou motivações. Nesse particular, a abordagem da fenomenologia de Alfred Schutz aprofunda e estende os sentidos da ação.

A elaboração da significância das relações entre o ator e sua própria ação, por Schutz (1974), implica reconhecermos que todo conhecimento sobre o mundo, em sentido comum ou científico, é construção, isto é, um conjunto de abstrações e formalizações inerentes à organização do pensamento humano. O que o autor evidencia-nos é que os sentidos da ação humana são fabricados pela atividade de nossa mente, o que permite a constatação da incapacidade humana para captar a realidade em plenitude, apenas alguns de seus aspectos.

Assim, se a realidade é suficientemente ampla, tanto que nos incapacita em sua percepção integral, os sentidos de nossa ação social são construídos na mesma razão. Como interpretamos, pois, nossa ação ou a realidade em que vivemos, então?

Toda interpretação deste mundo se baseia em um acervo de experiências prévias, que são nossas ou nos tem sido transmitidas por pais ou professores. Essas experiências funcionam como um esquema de referência em forma de "conhecimento à mão" (SCHUTZ, 1974, p. 39)

Este acervo de conhecimento à mão é constituído por nosso reconhecimento de que o mundo em que vivemos é organizado por objetos mais ou menos determinados, com certas qualidades sob as quais nos movemos, em resistência ou dando-nos condições de agir. Esses saberes situam-se em horizontes de familiaridade e vivência prévia do ator social, do mesmo modo suas experiências anteriores (ou prévias) típicas, ou que possam apresentar horizontes abertos de experiências similares antecipadas (SCHUTZ, 1974). Esses conhecimentos à mão atribuem um novo sentido à ação social.

Para o filósofo, o termo ação designa a conduta humana como processo em curso que é pensado pelo ator de antemão, isto é, que se baseia em um projeto preconcebido (SCHUTZ, 1974, p. 86). Como correlato, Schutz define o "ato", como o resultado deste processo de ação em curso. Não obstante a outros entendimentos, todos os projetos de atos futuros se baseiam nos conhecimentos que o ator dispõe à mão no momento de sua projeção, os quais constituem-se de seus acervos de experiências vivenciadas, suas efetuações, suas condições de interação social e intersubjetividade. Se o indivíduo orienta-se pela ação dos outros para definir sua própria ação (WEBER, 2008), então determina sua conduta futura ao considerar o curso de uma série de ações possíveis (SCHUTZ, 1974), sendo assim viável pensar que define sua ação desde um projeto preconcebido.

A ação, nessa perspectiva, pode ser definida como latente ou manifesta, embora nem toda conduta projetada possa ser dotada de propósito. Mas, seguramente, toda projeção consiste na antecipação da conduta futura através da imaginação (idem, p. 87). Da contribuição teórica da fenomenologia, exposta até 
aqui, provocamos ainda alguns questionamentos sobre as motivações à ação, face às múltiplas projeções possíveis, entre ações latentes e manifestas.

Schutz vai afirmar que as ações, segundo determinadas condições, são condutas motivadas, entendendo a expressão 'motivo' com uma dupla potencialidade heurística: "motivos para" e "motivos porque". Motivo 'para' significaria o estado de coisas, ou o objetivo imediato que se pretende atingir por uma ação, alinhando-se com interesses futuros do ator, no entanto, sem projetar. Por outro lado, o motivo 'porque' dirige-se a experiências já vivenciadas, portanto o que motiva esse tipo de ação é o projeto mesmo da ação. Assim, as motivações que se referem às vivências individuais dos atores são aquelas que constituem-se em condições de possibilidade para os mesmos projetarem suas ações.

O projeto pode ser entendido, inicialmente, como um pensar de modo potencial, ou como definira George Herbert Mead (1982, orig. 1934, p. 173), o pensamento como preparação à ação. No entanto, a efetuação de um projeto se dá em sua prática, ou desde fundamentos da praticabilidade. Conforme Alfred Schutz (1974), existem dois supostos de praticabilidade para a ação projetada: o mundo pressuposto e a situação biograficamente determinada. $\mathrm{O}$ mundo pressuposto consiste no conjunto das experiências do ator e seus referentes ao mundo, ao mundo físico e ao mundo social, são seus conhecimentos à mão, com os quais o indivíduo opera a elaboração de seu projeto. A situação biograficamente determinada responde às motivações ou aos propósitos da projeção, assim:

A esta situação biograficamente determinada pertence não somente minha posição no espaço, no tempo e na sociedade, mas também minha experiência de que alguns elementos do mundo pressuposto me sejam impostos, enquanto controlo ou possa controlar outros, que, por conseguinte, são principalmente modificáveis (SCHUTZ, 1974, p. 93).

A conjunção analítica entre o mundo pressuposto e a situação biograficamente determinada oportuniza a observação de que a situação atual do ator tem uma história, sedimentada por experiências subjetivas prévias, que não são fabricadas em anonimato, senão como únicas e construídas unicamente pelo próprio ator em relação à sua ação em circunstâncias determinadas. Assim sendo, seu projetar se faz tangenciado por sua vontade, mas nos limites do praticável, ou o que um antropólogo brasileiro denominaria de "campo de possibilidades" (VELHO, 1994).

Neste campo de possibilidades, podemos compreender que todo projetar é construção do indivíduo, sob algumas condições que lhes sejam controladas, mas antes de ensaiar ou imaginar os cursos futuros de sua ação, o resultado da ação projetada não está a seu alcance, isto é, no momento da projeção não existem projetos de ação a escolher. Tudo que posteriormente exigir a escolha do ator, entre seus diversos projetos, será produzido por ele mesmo e modificado 
Política, trajetória e formação dos atores culturais:

uma análise dos projetos contemporâneos

em situações definidas. Na próxima seção textual, diante da revisão conceitual ora feita, realizaremos uma descrição de duas trajetórias individuais, interessados em verificar como estes projetos podem ser identificados no plano empírico.

\section{Relações entre os atores e as políticas culturais: duas trajetórias}

Quando fazemos uso da noção de trajetória, procuramos acompanhar toda uma discussão posta na Antropologia brasileira acerca das biografias, histórias de vida e trajetórias pessoais (VELHO, 1986), no sentido de observarmos a complexidade das redes de significado nos níveis biográficos, suas contradições e seus conflitos. Trataremos, pois, da noção de trajetória como espaço de produção da experiência (DUBET, 1994) do ator social, concomitantemente, como espaço de mediação das crenças, costumes, idealizações, práticas e projetos culturais. Deste modo, entendemos que a trajetória pessoal é o que medeia a condição da existência de uma coletividade e os projetos culturais que concorrem para suas demandas, ou seja, é no plano das trajetórias individuais que os projetos de ação dos atores negociam a sua efetuação (SCHUTZ, 1974) com as condições político-culturais de nosso tempo.

A fim de ilustrarmos essa formulação, passamos a descrever duas trajetórias de atores culturais, atuantes em Canela, na Serra Gaúcha, os quais temos acompanhado ${ }^{3}$.

Luiz Paulo ${ }^{4}, 40$ anos, começou ainda no Ensino Médio a estudar e obter conhecimentos sobre música. Nos idos de 1982, realizava aproximações mais sistemáticas com a atuação cultural: tocava violão em festas, no Centro de Tradições Gaúchas, para os amigos e em momentos familiares. Mas, em 1987, começou a fazer teatro e suas vivências com o mundo artístico revelaram-se como possibilidades de profissão. Aprendeu, mediante trocas com pessoas de outros lugares que iam para Canela/RS, a atuar, aprendeu também perspectivas de cenário, iluminação e outros elementos relevantes na produção de um espetáculo de arte.

No mesmo ano, inicia um movimento de consolidação do teatro na cidade. Vários jovens começam a trabalhar em um projeto chamado Festival de

${ }^{3}$ Do ponto de vista metodológico, cumpre admitirmos que estaremos apresentando excertos da trajetória destes atores, os quais foram retirados de entrevistas que realizamos e constituem-se em material investigativo que estamos utilizando na produção da pesquisa para a formulação de Tese de Doutorado em Ciências Sociais.

${ }^{4}$ Neste texto, nossos informantes serão tratados por pseudônimos, a fim de preservar-lhes as identidades. 
Teatro de Canela, por iniciativa da prefeitura local, que passou a agenciar contatos com instituições do meio artístico presentes na capital do Estado. Artistas, atores, músicos, produtores e agentes culturais começam a trabalhar e circular em suas praças e palcos. O festival, então, era planejado para duas semanas, sendo a primeira para o teatro amador (comunitário) e a segunda (cerca de cinco dias) para profissionais vindos de outras regiões do país, ou outros países, além de Porto Alegre. Canela, na época, possuía vinte e dois grupos comunitários de teatro.

Esses artistas locais foram aprendendo estas técnicas, mas também aprenderam a organizar um evento, a formular projetos artísticos e culturais, a transitar pelo meio teatral e da cultura. Luiz Paulo chegou a viajar, com grupos de teatro, no fim dos anos 1980 e início dos 1990, por vários estados do Brasil. Estes aprendizados o fizeram profissional.

O festival de teatro ganhou dimensões relevantes, chegando a atingir a continuidade de dez anos, contribuindo para a produção de outro evento, no mesmo período, o Festival de Teatro de Bonecos de Canela. Esse evento era o mais importante evento de teatro do Estado, o que mudou logo depois da criação de eventos desta ordem em Porto Alegre.

Nosso informante ressaltou que o Festival de Teatro teve um efeito de formação ou, em suas palavras, de capacitação. Os mesmos atores que apresentavam as peças, assim como outros profissionais do ramo, ficavam mais de uma semana na cidade, antes ou após o festival, ministrando oficinas de sonorização, iluminação, vocalização e outras. Canela vivia um mês todo de teatro, enquanto os grupos trabalhavam o ano todo nas peças a apresentar. Atores e diretores de renome internacional vinham ao município, por recursos próprios, para assistirem peças e atuarem nos espaços formativos dos jovens artistas.

Daqueles jovens canelenses poucos profissionalizaram-se. Mas Luiz encontrou, apesar das dificuldades, condições de trabalhar e viver até hoje destas atuações. Consoante a suas observações, os festivais de teatro declinaram, no início nos anos 2000, por motivos políticos e de financiamento, mas o mesmo passou a acionar seus contatos e formular projetos culturais vinculados a associações culturais na cidade e no Estado. Trabalha, atualmente, em projetos de prefeituras, em cultura e turismo. Vincula-se, hoje, à Confraria da Cultura, uma associação de artistas locais que se reúnem para estudar, discutir, propor e planejar eventos e políticas culturais. Também mantém vinculação a uma Associação Cultural que realiza ações na promoção de eventos como o Sonho de Natal, em Canela, e em outros dois municípios do Estado: Osório e Nova Petrópolis.

Apesar dos vínculos, desenvolve uma carta de projetos própria. $\mathrm{Na}$ condição de produtor independente, é contratado para desenvolver e coordenar diversos projetos, dando-lhes formato artístico, atuando em diversas funções: produção, seleção de atores na comunidade, agenciamento de patrocinadores e recursos de financiamento, pagamento dos cachês e a própria direção artística dos espetáculos.

Quando analisa sua trajetória profissional, admite que ganhou experiência trabalhando em eventos. Comenta que seus colegas de palco nos anos de 1980 aprendiam a desenvolver uma peça teatral, trabalhavam um ano todo,

Latitude, vol. 4, № 1, pp.74-90, 2010 
Política, trajetória e formação dos atores culturais:

uma análise dos projetos contemporâneos

apresentavam a peça e desfaziam-se de tudo. Preparavam-se para um evento único. Ele, aos poucos, foi observando que o mesmo evento pode ser aprimorado e vendido para diferentes lugares, ganhando lucros com isso.

A partir de sua própria experiência, afirma que costuma envolver-se em projetos que possam investir na formação e capacitação de atores locais. Acredita que essas ações culturais devam capacitar estudantes e interessados para que possam também aprender um ofício: atuação, sonorização, iluminação. Desde 2007, quando passou a dirigir os Desfiles de Natal, atrelado ao evento natalino da cidade, tem-se ocupado de investir na seleção de atores da comunidade, sendo que atuaram naquele ano 60 pessoas e, no ano seguinte, 130. Sua carta de projetos vem, portanto, sendo vendida a várias entidades culturais de municípios próximos, a qual prioriza iniciativas que se pretendam formativas de jovens não-iniciados no meio artístico-teatral, tendo por finalidade última, segundo destaca, a formação cidadã dos participantes.

João Carlos, 44 anos, nasceu em Caxias do Sul/RS. Iniciou suas atividades profissionais no setor metalúrgico, atuando em técnicas e processos de controle de qualidade, uma vez que havia realizado alguns cursos voltados à formação de torneiro mecânico, fornecidos pelo Serviço Nacional da Indústria (SENAI).

Trabalhou na indústria por muitos anos. Começou, portanto, como torneiro mecânico, mas, em seguida, por diversos motivos acabou frustrando-se com a função e com a empresa e decidiu procurar novos rumos para sua carreira, mesmo tendo já alguns anos de experiência e um currículo qualificado. Então, com 22 anos, começa a trabalhar em uma ferramentaria, outra fase de sua trajetória profissional inicia: inserir-se em ações que envolviam tecnologia de alta precisão. Essa nova empresa, desenvolvia inúmeros produtos, mas sua especialidade era o desenvolvimento de coberturas para pavilhões. Porém, é novamente chamado a coordenar o controle de qualidade, mas, dessa vez, com uma considerável diferença, o salário era nove vezes maior do que recebia anteriormente.

Com o aumento significativo de sua renda, João passou a realizar investimentos em uma de sua paixões desde a infância, a arte e, especialmente, o teatro. Frequentava todos os espetáculos de teatro de Caxias do Sul, assim como todos os shows de música, de diferentes estilos ou formas de expressão. Consequentemente, tornou-se amigo dos atores, até que recebeu um convite para associar-se ao grupo e, convite aceito, criaram uma produtora cultural, nos anos de 1980.

Esta sua empresa veio a produzir, dois anos depois, um espetáculo de teatro de bonecos, o qual João nunca havia assistido, segundo seu depoimento, nem mesmo sabia que existia. Aquela apresentação foi muito significativa, por um lado, foi de uma beleza ímpar, mas, por outro, despertou-lhe a percepção e o desejo de desenvolver aquela arte. Começou a fazer isso um mês depois. Pouco tempo depois, é convidado e vem a atuar com o mesmo grupo que produziu e, 
definitivamente, abandona a medição de ferramentas e as atividades na ferramentaria. Permaneceu atuando com este grupo teatral por quatro anos, viajando todo o Rio Grande do Sul, colaborando, inclusive, na produção e divulgação do mesmo.

No início da década seguinte, viajaram a Florianópolis para um conjunto de apresentações, no entanto, devido à crise do dólar, o lucro esperado não se concretizou e o grupo se desfez. Seus colegas e amigos desistiram das atividades teatrais e João decide ter persistência e cria o grupo "Só Rindo". Trabalhou por um tempo em Santa Catarina e, depois, voltou a sua terra natal onde acabou conhecendo sua companheira Cristina. Juntos, viajam o Estado inteiro, andam por vários Estados do Brasil, realizam inúmeros cursos, apresentam-se em vários festivais de teatro de bonecos, com muitos profissionais. Nestes interstícios, vai desenvolvendo um processo autodidata de aprendizagem e encanta-se pelo lixo, pelo material reciclado. Desde então, trata de aprimorar técnicas que utilizam esse material.

Quando fala de si, destaca que realizou quinze anos de teatro de bonecos na rua, de praça, de calçada, de festival, das vezes em que teve que entrar pela tangente - na contramão da programação oficial de alguns eventos, para chegar a ter o reconhecimento profissional que tem hoje. Considera-se conhecido e bom profissional.

Ao mencionar seus aprendizados, fala das viagens internacionais que tem realizado, recentemente. Participou de festivais em muitos países da América Latina e na China. Relata que sua experiência no Peru foi muito interessante: eram oito grupos e, além de espetáculo, cada grupo deveria oferecer uma oficina. João explica:

A gente fez oito oficinas, oficinas de objetos, só pra bonequeiros, com um grupo americano. Sempre tem isso. O mais legal é você... é legal você estar em um espetáculo em um grande teatro, mas nesses festivais é sempre assim, você faz uma no teatro e outra na descentralização. [...] Participação permanente em oficinas, é legal ver como o outro grupo trabalha. Te ajuda a desenvolver umas perspectivas novas (João, 46 anos, bonequeiro).

Segundo seu depoimento, a profissão do bonequeiro baseia-se no autodidatismo no Brasil. Existem várias escolas, mas nenhuma entidade que forme o bonequeiro, não há nem o reconhecimento como categoria profissional. $\mathrm{O}$ aprendizado do teatro de bonecos, em sua experiência, consistiu em algumas atividades: leitura, assistir o que os outros artistas desenvolvem, visitar profissionais mais experientes e frequentar festivais. 
Política, trajetória e formação dos atores culturais:

uma análise dos projetos contemporâneos

Desde 2004, João reside em Canela, quando passou a participar do Festival Internacional de Teatro de Bonecos, evento que ocorre na cidade há vários anos. Além disso, passou a desenvolver um conjunto de iniciativas voltadas a crianças e jovens do município: ações de sensibilização para a arte em escolas públicas municipais, oficinas de dramatização, iluminação, confecção de bonecos. Essas ações estavam orientadas por duas linhas de trabalho: a formação de público para os espetáculos de teatro de bonecos e formação artística destes jovens que, em geral, são moradores da periferia da cidade. As experiências desenvolvidas nas escolas, em parceria com a Fundação Cultural de Canela, potencializaram a formulação de um projeto concorrente a um Ponto de Cultura - ação pública destinada à descentralização do acesso à arte, promovido pelo Ministério da Cultura.

Após o processo seletivo, em 2008, iniciam as atividades do Ponto de Cultura. Esse projeto estava focado na formação artística de sessenta estudantes, distribuídos em três turmas, nas quais são ministradas oficinas de: iluminação, sonorização, produção, contra-regragem, fotografia, edição de vídeo e comunicação (produção textual, jornal, blogs e sites, internet). O horizonte do projeto, que envolve estudantes do ensino médio, é a profissionalização dos participantes voltada aos eventos turísticos que são promovidos na região, segundo destaca seu idealizador.

Atualmente, João segue atuando em seus projetos de produção independente, na formação dos estudantes no Ponto de Cultura e em alguns projetos realizados por órgãos de assistência social e cidadania vinculados à Prefeitura Municipal de Canela.

\section{Projetos contemporâneos e os novos repertórios de ação}

As trajetórias de atores culturais narradas na seção textual anterior permitem algumas análises sobre os projetos culturais na contemporaneidade, sobremaneira evidenciados nas relações entre as mesmas trajetórias e as políticas culturais ${ }^{5}$ em que atuam. Mais especificamente, estas novas relações formulam outras exigências para a ação dos atores ou, pela hipótese que estamos interessados em desenvolver neste texto, o permanente apelo à formação dos atores culturais faz-se condição para novos repertórios de ação. A elaboração de Schutz (1974) sobre os "conhecimentos à mão", os quais seriam elementos mediadores da interpretação da realidade social e suporte à ação na mesma, faz-se ponto de partida para que possamos propor alguns nexos interpretativos sobre as ações dos atores estudados. Argumentaremos, pois, que os agenciamentos de recursos e a formação cultural dos atores culturais são constituintes dos repertórios de ação nessa sociedade, atualizando as considerações oportunas do filósofo. O que

5 Para leituras mais específicas das práticas de políticas culturais, ver: Canclini (1987) e Calabre (2003). 
significa considerarmos, inicialmente, que os projetos de ação na cultura, em nosso tempo, elaboram-se sob novas exigências, as quais passaremos a mencionar.

François Dubet, em sua Sociologia da Experiência (1996), destaca o caráter ambíguo que a ideia de experiência encerra, uma vez que a mesma remete a dois fenômenos contraditórios que o próprio sociólogo trata de vincular. Por um lado, a experiência é um modo de sentir, de sofrer um estado emocional suficientemente forte que acabe por inibir a liberdade do ator, ao mesmo passo em que constrói sua subjetividade (DUBET, 1996, p. 94). Por outro lado, a referida ideia pode ser entendida como atividade cognitiva, maneira de construir o real ou de experimentá-lo. Desde essa ambivalência da representação da experiência, entre o estado emocional e a atividade cognitiva, consideramos que a experiência não é uma 'esponja', ou seja, um modo de incorporar o mundo pelas emoções e sensações, mas um modo de construir o mundo (DUBET, 1996).

A experiência adquire sentido, portanto, quando a ação não se torna redutível à versão subjetiva do sistema, se o ator não estiver plenamente socializado, por assim dizer, a ação perde sua unidade e deixa de ser redutível a um programa único. Desta maneira:

A socialização não é total, não porque o indivíduo escape ao social, mas porque a sua experiência se inscreve em registros múltiplos e não congruentes (DUBET, 1996, p. 98).

A produção das experiências sociais dos atores, em seus múltiplos registros, demonstra-nos que os sentidos da ação são inúmeros e constituintes de repertórios. Desses repertórios, em nosso tempo, integram os projetos de ação (SCHUTZ, 1974) mobilizados desde as condições de agenciamento de recursos dos atores e os processos formativos que lhe dão consistência a partir de cursos possíveis de ação. Nas palavras de Certeau (1994), face à multiplicidade destes registros, as trajetórias individuais se indeterminam.

Na situação de Luiz Paulo e João Carlos, que analisamos aqui, parecenos que seus cursos de ação indeterminaram-se face às redefinições políticoculturais de nosso tempo, as quais têm oportunizado múltiplas condições à produção de sua experiência social, mas, ao mesmo tempo, permite que os atores reelaborem projetos de ação diante das próprias mudanças. Partindo da trajetória de cada um dos atores analisados, observamos que seus processos formativos são elaborados desde suas circunstâncias biográficas, nos fazeres e experiências de apresentação de teatro amador, no entanto, há um momento determinado em suas trajetórias que permite que profissionalizem-se. Quando o fazem, seus cursos de ação são refeitos e passam a projetar outras expectativas pessoais em torno do teatro.

Por um registro mais amplo, cabe destacarmos que as redefinições político-culturais em nosso tempo demarcam a transição da cultura ao centro das 
Política, trajetória e formação dos atores culturais:

uma análise dos projetos contemporâneos

esferas econômicas, políticas e sociais. Para caracterizarmos o contexto contemporâneo, fazemos uso das palavras de George Yudice:

Hoje em dia é quase impossível encontrar declarações públicas que não arregimentem a instrumentalização da arte e da cultura, ora para melhorar as condições sociais, como na criação de tolerância multicultural e participação cívica através de defesas como as da UNESCO pela cidadania cultural e por direitos culturais, ora para estimular o crescimento econômico através de projetos de desenvolvimento cultural urbano e a concomitante proliferação de museus para o turismo cultural (YUDICE, 2004, p. 27).

Assim, a cultura constitui-se em espaço estratégico de negociação econômica e política das realidades (VELHO, 1994). O que se altera, de modo significativo, são as tipicidades de cursos de ação possíveis (SCHUTZ, 1974) em uma sociedade em que a cultura se torna uma "reserva disponível" para os projetos desenvolvidos (YUDICE, 2004). Assim sendo, se a cultura torna-se uma reserva objetiva de recursos disponíveis, a efetuação de um projeto dependerá da capacidade dos atores em agenciarem recursos para o desenvolvimento de suas ações, o que permite que se reconheça o quanto George Yudice atualiza a concepção de agência de Alfred Schutz. Para Schutz (1974), a concepção de agência sugere que os projetos, enquanto planos ou cursos de ação possíveis, seriam embasados nas potencialidades dos conhecimentos à mão, os quais produzem sentidos à ação. Por este viés, memória, recursividade ou identidade seriam motivações próprias à ação .

Yudice (2004), por sua vez, provoca reflexões sobre os usos da cultura na contemporaneidade, sendo que o agenciamento de recursos é condicionado pelo próprio uso conveniente que é feito da cultura. Com isso, o autor contribui para um entendimento imanente da cultura, pelo qual esta se torna gerida pela performatividade na ação dos atores, pois: "a conveniência da cultura sustenta a performatividade como lógica fundamental da vida social de hoje" (YUDICE, 2004, p. 50). O agenciamento de recursos necessários à implementação de um projeto cultural é oportunizado por seu uso conveniente, enquanto recurso para atingir um fim, ao mesmo tempo em que efetua-se por forças performativas que demarcam imperativos sobre a relação entre sujeitos e sociedade.

Hoje parece-nos que há uma emergência destes processos e, sobretudo, da necessidade dos atores de agenciarem recursos para o desenvolvimento de projetos na/para/pela cultura, o que fica explícito sob várias angulações: desde a constante presença de editais públicos e privados destinados ao financiamento de projetos culturais voltados a fins diversos, como o Ponto de Cultura identificado na trajetória de João Carlos; a busca de constituição de redes sociais visando interlocução e consolidação de grupos culturais voltados a fins 
próprios; ou ainda o apelo à formação dos atores culturais para atuação nestas dinâmicas, presentes nas narrativas de nossos informantes.

As transformações societárias recentes atribuem centralidade à cultura, a qual passa crescentemente à redirecionar ou redefinir os projetos elaborados pelos atores sociais. Desde a trajetória e os projetos desenvolvidos por João Carlos, podemos compreender que algumas destas iniciativas exigem constantes processos formativos que atualizam os repertórios de ação dos sujeitos desde uma dupla percepção: a formação cultural torna-se exigência à ação dos atores culturais em nosso tempo, tornando-se formação permanente, e faz-se condição de possibilidade à própria ação, quando o mesmo profissionaliza-se. Essa ambiguidade da formação cultural, delimitadora e potencializadora da ação social, seria uma síntese dos projetos e políticas culturais contemporâneas.

No entanto, o caso de Luiz Paulo, brevemente tratado neste texto, nos provoca pensar que a formação situa-se para além do jogo ambíguo da delimitação-potencialização da ação social, pois a formação constitui-se em elemento da produção da experiência social dos atores. Ou seja, os projetos formulados dependem dos conhecimentos à mão trazidos, mas os conhecimentos à mão são mobilizados na razão em que operacionalizam ou efetuam projeções.

Em parte, o que salientamos é que a formulação destes projetos é negociada no plano das interações sociais, entre agentes portadores de projetos individuais e coletivos distintos, dentro de um determinado campo de possibilidades. Essa condição de possibilidade oportuniza que, desde trajetórias e projetos, os atores agenciem recursos para formular e implementar suas projeções. Acreditamos que semelhante dinâmica ocorra com as políticas culturais na contemporaneidade, de maneira que mesmo sob as transformações do capitalismo vigente que alteram o estatuto dos usos da cultura (YUDICE, 2004), há formulações e reformulações dos projetos culturais quando alinhados aos projetos individuais em trajetórias de vida específicas. Portanto, as experiências sociais vivenciadas por Luiz e João ao longo de suas trajetórias orientam suas ações político-culturais, associando-se aos diversificados conhecimentos aprendidos nos projetos sociais onde atuam, o que comporia, então, seus repertórios de ação. Suas vivências, assim como suas memórias, dão consistência a seu projeto, tal como explicita a citação abaixo:

A consistência do projeto depende, fundamentalmente, da memória que fornece os indicadores básicos de um passado que produziu as circunstâncias do presente, sem a consciência das quais seria impossível ter ou elaborar projetos (VELHO, 1994, p. 101).

Por isso mesmo,

o projeto é dinâmico e é permanentemente reelaborado, reorganizando a memória do ator, dando novos sentidos 
Política, trajetória e formação dos atores culturais:

uma análise dos projetos contemporâneos

e significados, provocando com isso repercussões na sua identidade (VELHO, 1994, p. 104).

A experiência já vivenciada pelos atores dá uma dimensão retrospectiva à ação, oferecendo-lhe registros identitários, mas a atualidade de sua formação permanente dimensiona prospectivas de ação ao indivíduo. Nesta linha, interpretamos que os cruzamentos entre a dimensão retrospectiva e a prospectiva situam os indivíduos no curso de suas ações possíveis (SCHUTZ, 1974), tanto quanto motivam e significam suas trajetórias (VELHO, 1986; 1994) e lógicas de ação política.

A formação dos atores culturais, portanto, dá outras condições ao agenciamento de recursos realizado pelos atores, produzindo novos sentidos à ação na contemporaneidade. Desde os relatos de trajetória que apresentamos, conseguimos reconhecer que as iniciações realizadas pelos estudantes em teatro, dança ou música não somente ressignificam sua ação, mas potencializam sua experiência social - acompanhando um tendência atual em investimentos na formação cultural dos atores.

Para concluir, no contraste entre os dados empíricos que coletamos e os aspectos teóricos supracitados, destacamos que, no plano de construção das políticas para o setor da cultura, estas trajetórias têm exigido que os atores mobilizem táticas e estratégias (CERTEAU, 1994) com interesse de qualificar sua atuação, profissionalizando-se, face à demanda constante por espaços formativos e de capacitação específica enquanto condição para o agenciamento de recursos (YUDICE, 2006) para seus projetos. Esse horizonte formativo redefine as justificativas destes projetos culturais, sob a égide da cidadania, as quais passam a abrir espaço para a formação de novos atores culturais e de novos públicos, intensificando e multiplicando, por assim dizer, os circuitos culturais de teatro no âmbito regional. 


\section{Bibliografias}

CALABRE, Lia. Política cultural no Brasil: um histórico. In: (org.) Políticas culturais: diálogo indispensável. Rio de Janeiro: Ed. Casa Rui Barbosa, 2003. pp. 920.

CANCLINI, Néstor Garcia (org.). Políticas Culturales en América Latina. Barcelona: Grijalbo, 1987.

CERTEAU, Michel. A invenção do cotidiano (Vol. I: Artes de Fazer). Petrópolis: Vozes, 1994.

DUBET, François. Sociologia da Experiência. Lisboa: Instituto Piaget, 1996.

FERNANDES, Florestan. A Herança Intelectual da Sociologia. In: FORACCHI, M. M.; MARTINS, J. S. (orgs.) Sociologia e Sociedade: leituras de introdução à Sociologia. Rio de Janeiro: LTC, 2008.

MEAD, George Herbert. Espíritu, Persona, Sociedad. Buenos Aires: Paidós, 1982.

OLIVEIRA, Pedro; VEECK, Marcelo Wasem; REIS, Antônio Olmiro. Canela por muitas razões. $2^{\mathrm{a}}$ Ed. Porto Alegre: EST, 2009.

SCHUTZ, Alfred. El problema de la realidad social. Buenos Aires: Amorrortu, 1974.

SIMMEL, Georg. Sociabilidade: um exemplo de sociologia pura ou formal. In: MORAES FILHO, Evaristo (org.) Simmel: Sociologia. São Paulo: Ática, 1983.

STOLTZ, Roger. Primórdios de Canela: Nascente Turístico do Rio Grande do Sul. Canela: Fundação Cultural de Canela, 1992.

TÖNNIES, Ferdinand. Comunidade e sociedade. In: FERNANDES, Florestan (org.). Comunidade e Sociedade. São Paulo: Nacional/Edusp, 1973.

VELHO, Gilberto. Subjetividade e Sociedade: uma experiência de geração. Rio de Janeiro: Zahar, 1986.

Projeto e metamorfose: antropologia das sociedades complexas. Rio de Janeiro: Zahar, 1994.

Latitude, vol. 4, no 1, pp.74-90, 2010 
Política, trajetória e formação dos atores culturais:

uma análise dos projetos contemporâneos

WEBER, Max. Ação social e relação social. In: FORACHI, M. M.; MARTINS, J. S. Sociologia e Sociedade: leituras de introdução à sociologia. Rio de Janeiro: LTC, 2008.

YUDICE, George. A conveniência da cultura: usos da cultura na era global. Belo Horizonte: Editora UFMG, 2004. 